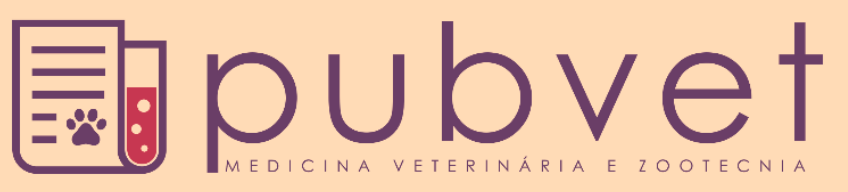

https://doi.org/10.31533/pubvet.v14n11a696.1-7

\title{
Osteossíntese tibial com fixador esquelético externo tipo II em um caprino
}

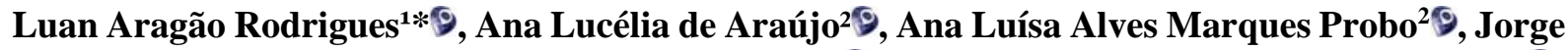 \\ Domigos da Silva Lima ${ }^{1}$, Gerôncio Sucupira Júnior ${ }^{3 \mathbb{9}}$, Fabrícia Geovânia Fernandes Filgueira ${ }^{3 \mathbb{9}}$, \\ Rodrigo Formiga Leite ${ }^{309}$
}

${ }^{1}$ Aluno do Curso de Especialização em Medicina Veterinária do Instituto Federal da Paraiba, Hospital Veterinário Adilio Santos de Azevedo. Sousa - PB Brasil. ${ }^{2}$ Professora do Instituto Federal da Paraíba, Sousa - PB Brasil.

${ }^{3}$ Médico veterinário do Instituto Federal da Paraíba, Hospital Veterinário Adílio Santos de Azevedo. Sousa - PB Brasil.

*Autor para correspondência, E-mail: luan.veterinaria@gmail.com

Resumo. O objetivo deste trabalho foi relatar o caso de um caprino com fratura transversa de tíbia submetido a osteossíntese com fixador esquelético externo tipo II. Uma cabra foi atendida no Hospital Veterinário Adílio Santos de Azevedo do IFPB no campus de Sousa - Paraíba com queixa de claudicação do membro pélvico esquerdo, sendo diagnosticada fratura fechada transversa no terço médio de tíbia. Foi realizada imobilização externa do membro com gesso, porém não houve melhora, sendo necessária a osteossíntese com uso de fixador esquelético externo tipo II. Observou-se o apoio claudicante do membro operado no dia seguinte a cirurgia. Os pontos de pele foram retirados treze dias após o procedimento cirúrgico, pois a ferida estava cicatrizada e sem alterações. $O$ animal ficou internado durante os 25 primeiros dias após a cirurgia, após esse período o animal foi encaminhado de volta a propriedade com a recomendação da limpeza do fixador esquelético externo a cada dois dias e o isolamento do animal até a retirada. Sessenta e oito dias após o procedimento cirúrgico, o animal estava sem apoiar o membro, com secreção purulenta drenando pelo trajeto dos pinos e por ferida penetrante na região lateral do membro pélvico, frouxidão dos pinos e dor a manipulação. $\mathrm{O}$ exame radiográfico revelou lise óssea no trajeto dos pinos. O implante foi retirado e prescrito medicação com antibiótico e analgésico. Após vinte dias desse último atendimento, o animal retornou ao $\mathrm{HV}$ com as feridas cicatrizadas, sem dor à palpação e apoio intermitente do membro, podendo observar também um desvio no local da fratura devido à má união óssea. Conclui-se que apesar das complicações póscirúrgicas, o animal se recuperou da fratura com o uso de fixador esquelético externo tipo II, pois mesmo não havendo a continuidade de manejo pós-cirúrgico adequado, houve união clínica da fratura.

Palavras chave: cabra, fratura, ortopedia, pós-cirúrgico

\section{Tibial osteosynthesis with type II external skeletal fixator in a goat}

Abstract. This study aimed to report the case of a goat with a transverse tibial fracture submitted to osteosynthesis with type II external skeletal fixator. A goat was seen at the Veterinary Hospital Adílio Santos de Azevedo of the IFPB on the Sousa - Paraíba campus, complaining of lameness of the left pelvic limb, and a transverse closed fracture in the middle third of the tibia was diagnosed. External immobilization of the limb with plaster was performed, but there was no improvement, requiring osteosynthesis with the use of type II external skeletal fixator. The limb support of the operated limb was observed the day after the surgery. The skin stitches were removed thirteen days after the surgical procedure, as the wound was healed and unchanged. The animal was hospitalized during the first 25 days after surgery, after which the animal was sent back to the property with 
the recommendation of cleaning the external skeletal fixator every two days and isolating the animal until removal. Sixty-eight days after the surgical procedure, the animal was without supporting the limb, with purulent secretion draining through the pins path and a penetrating wound in the lateral region of the pelvic limb, looseness of the pins, and pain on manipulation. Radiographic examination revealed bone lysis along the pins' path. The implant was removed and medication with antibiotics and analgesics was prescribed. After twenty days of this last visit, the animal returned to the HV with the wounds healed, without pain on palpation and intermittent support of the limb, and may also observe a deviation at the fracture site due to bad bone union. It is concluded that despite the post-surgical complications, the animal recovered of the fracture with the use of a type II external skeletal fixator because even though there was no continuity of adequate post-surgical management, there was a clinical union of the fracture.

Keywords: goat, fracture, orthopedics, post-surgical

\section{Osteosíntesis tibial con fijador esquelético externo tipo II en una cabra}

Resumen. El objetivo de este estudio fue informar el caso de una cabra con una fractura tibial transversal sometida a osteosíntesis con fijador esquelético externo tipo II. Se atendió una cabra en el Hospital Veterinario Adílio Santos de Azevedo del IFPB en el campus de Sousa - Paraíba quejándose de cojera en la extremidad pélvica izquierda, y se diagnosticó una fractura cerrada transversal en el tercio medio de la tibia. Se realizó la inmovilización externa de la extremidad con yeso, pero no hubo mejoría, requiriendo osteosíntesis con el uso del fijador esquelético externo tipo II. El soporte de la extremidad operada se observó el día después de la cirugía. Los puntos de la piel se retiraron trece días después del procedimiento quirúrgico, ya que la herida cicatrizó sin alteraciones. El animal fue hospitalizado durante los primeros 25 días después de la cirugía, después el animal fue enviado de vuelta a la propiedad con la recomendación de limpiar el fijador esquelético externo a cada dos días y el aislamiento del animal hasta su extracción. Sesenta y ocho días después del procedimiento quirúrgico, el animal estaba sin sostener la extremidad, con secreción purulenta drenada por el trayecto de los pinos y una herida penetrante en la región lateral de la extremidad pélvica, pinos flojos y dolor a la manipulación. El examen radiográfico reveló lisis ósea en el trayecto de los pinos. Se retiró el implante y se recetaron antibióticos y analgésicos. Después de veinte días de esta última visita, el animal regresó al HV con las heridas cicatrizadas, sin dolor a la palpación y soporte intermitente de la extremidad, y también si observó una desviación en el sitio de la fractura debido a una mala unión ósea. Se concluye que, a pesar de las complicaciones posquirúrgicas, el animal se recuperó de la fractura con el uso de un fijador esquelético externo tipo II, porque a pesar de que no hubo continuidad del manejo posquirúrgico adecuado, hubo una unión clínica de la fractura.

Palabras clave: cabra, fractura, ortopedia, postquirúrgico

\section{Introdução}

Dentre as afecções que acometem os pequenos ruminantes, as traumáticas possuem uma menor ocorrência (Borowsky et al., 2019), porém não apresentam menor importância. Os traumas ósseos, por exemplo, causam lesões de difícil resolução e podem culminar com eutanásia dos animais. Todavia, o melhor a ser feito é a prevenção que consiste em um bom manejo nutricional, controle sanitário e manejo genético.

As fraturas ocorrem principalmente em animais jovens, e são mais observadas no esqueleto apendicular, nos ossos do metacarpo e metatarso, seguidos por tíbia, rádio, ulna e úmero. Diversos são os tratamentos para correção das fraturas, variando de acordo com a sua configuração e localização (Zielinski et al., 2017).

Para tratamento de fraturas em pequenos ruminantes, existe o conservador e o cirúrgico. O conservador consiste na imobilização externa do membro, e o cirúrgico no procedimento operatório e 
colocação de implantes. Dentre estes, podem ser utilizados o fixador esquelético externo, pino intramedular, placas ósseas, haste intramedular e fios de aço (Piermattei et al., 2009).

Os fixadores esqueléticos externos (FEE) são divididos em meios pinos ou tipo I, eles atravessam duas corticais e são fixados unilateralmente. O tipo II, além de atravessar as duas corticais e os tecidos moles, são fixados bilateralmente. O tipo III são uma fusão do tipo I com o tipo II, tornando-se uma forma tridimensional (Conti et al., 2007).

Trabalhos que relatam a correção de fraturas em pequenos ruminantes são escassos, principalmente, aqueles que utilizam técnicas mais invasivas como a osteossíntese e utilização de implantes de fixação. Dessa forma, o objetivo deste trabalho foi relatar o caso de um caprino com fratura de tíbia, submetido a osteossíntese com fixador esquelético externo tipo II.

\section{Relato do caso clínico}

Uma cabra mestiça de aproximadamente três meses, pesando 7,5 kg, foi atendida no Setor de Clínica Médica e Cirúrgica de Grandes Animais do Hospital Veterinário Adílio Santos de Azevedo do Instituto Federal da Paraíba (HV-ASA/IFPB) no campus de Sousa - Paraíba, com histórico de trauma e suspeita de fratura do membro pélvico esquerdo (MPE).

No exame físico geral não foram observadas alterações nos parâmetros vitais, porém à inspeção, o animal apresentou claudicação do MPE. Ao exame físico ortopédico, identificou-se crepitação e dor na região da tíbia esquerda. Assim, o animal foi encaminhado para realização do exame radiográfico nas projeções craniocaudal (CC) e mediolateral (ML), que revelou fratura fechada transversa no terço médio de tíbia.

Em seguida, o paciente foi medicado com flunixim meglumine $(55 \mathrm{mg} / \mathrm{mL})$ na dose $1,1 \mathrm{mg} / \mathrm{kg}$ por via intramuscular (IM), e realizada a imobilização externa do membro com gesso sintético. O animal permaneceu internado no HV-ASA para acompanhamento. Sete dias depois, foi realizada a troca do gesso, uma vez que o anterior estava sem funcionalidade. Por se tratar de um animal jovem e ativo, cinco dias depois, realizou-se uma nova troca do gesso. Mesmo com a confecção da terceira imobilização, após o exame radiográfico observou-se o não alinhamento e aposição dos fragmentos ósseos.

Não foi obtido resultado com a coaptação externa, sendo assim, foi necessária a intervenção cirúrgica de osteossíntese que ocorreu 16 dias após o primeiro atendimento do paciente.

$\mathrm{O}$ animal foi submetido a jejum sólido de 12 horas e hídrico de 8 horas. Foi realizada a tricotomia e antissepsia prévia do membro a ser operado com clorexidine $2 \%$. O animal recebeu antibioticoterapia com amoxicilina $150 \mathrm{mg} / \mathrm{mL}$ na dose de $15 \mathrm{mg} / \mathrm{kg}$ e anti-inflamatório com meloxicam $0,2 \%$ na dose de $0,2 \mathrm{mg} / \mathrm{kg}$, ambos por via IM.

O protocolo anestésico consistiu em botão anestésico com $0,5 \mathrm{~mL}$ de lidocaína (1\%) com vasoconstritor, sendo $0,2 \mathrm{~mL}$ no espaço subcutâneo e $0,3 \mathrm{~mL}$ no ligamento amarelo da região lombossacra. Aguardou-se a latência do fármaco. Ato contínuo, foi realizada a anestesia locorregional epidural com lidocaína (2\%), com vasoconstritor $(1 \mathrm{~mL} / \mathrm{kg})$, bupivacaína $(0,5 \%)$, sem vasoconstritor $(1$ $\mathrm{mL} / \mathrm{kg})$, morfina $1 \%(1 \mathrm{mg} / \mathrm{kg})$ e dexmedetomidina $0,5 \%(0,046 \mathrm{mg} / \mathrm{kg})$. Aguardou a latência de 10 minutos para a manipulação do animal.

O animal foi mantido em decúbito lateral direito, realizou-se a antissepsia com clorexidine a $0,05 \%$, e posterior colocação dos panos de campo estéreis.

O procedimento cirúrgico consistiu em osteossíntese de tíbia com fixador esquelético externo (FEE) tipo II (Figura 1), e iniciou com a incisão sobre o foco da fratura, incidindo pele e subcutâneo. Observouse presença de tecido fibroso. Os fragmentos ósseos foram reduzidos manualmente. Introduziu-se com auxílio de furadeira dois pinos de 2,0 $\mathrm{mm}$ e um pino de $1,5 \mathrm{~mm}$ distais ao foco da fratura, e dois pinos de $1,5 \mathrm{~mm}$ proximais. Os pinos foram dobrados e cortados para posterior aplicação de barra acrílica (polimetilmetacrilato). O membro contralateral foi preparado com tricotomia e antissepsia para posterior coleta de medula óssea através da crista da tíbia, com auxílio de seringa de $20 \mathrm{~mL}$ e agulha 40 x $12 \mathrm{~mm}$. Foram coletados $2 \mathrm{~mL}$ de medula óssea que foram inseridos no foco da fratura. Foi realizada a redução 
de espaço subcutâneo com náilon 2-0, padrão de sutura vai-e-vem, e dermorrafia com náilon 2-0 e padrão Wolf.

No pós-operatório, o paciente recebeu amoxicilina $150 \mathrm{mg} / \mathrm{mL}$ na dose de $15 \mathrm{mg} / \mathrm{kg}$ a cada 48 horas durante sete dias, e anti-inflamatório meloxicam $(0,2 \%$ na dose de $0,2 \mathrm{mg} / \mathrm{kg}$ a cada 24 horas durantes três dias, ambos por via IM. Também foi realizada a limpeza da ferida cirúrgica e em torno do FEE com solução fisiológica, aplicação tópica de povidona e bandagem com atadura e esparadrapo. Nos primeiros cinco dias, o curativo foi realizado a cada 12 horas, e depois a cada 48 horas.

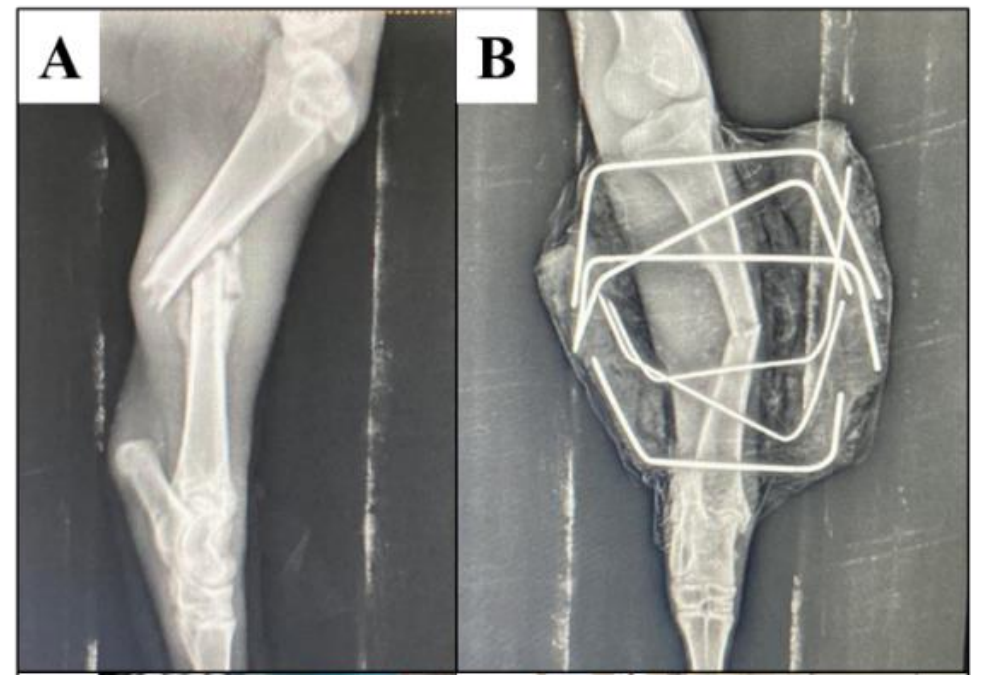

Figura 1. (A) Imagem radiográfica na projeção mediolateral da fratura transversa de terço médio de tíbia. (B) Imagem radiográfica na projeção craniocaudal do pós-cirúrgico imediato da osteossíntese de tíbia com fixador esquelético externo tipo II.

Observou-se o apoio claudicante do membro operado um dia após a cirurgia. Os pontos de pele foram retirados treze dias após o procedimento cirúrgico.

O animal ficou internado durante os 25 primeiros dias após a cirurgia, porém devido à paralização do HV-ASA ocasionada pela pandemia do COVID-19, a cabra foi encaminhada para a propriedade com a recomendação da limpeza da ferida cirúrgica a cada dois dias e o isolamento do animal até a retirada do FEE.

Sessenta e oito dias após o procedimento cirúrgico, o proprietário entrou em contato, relatando que o animal tinha sido solto junto com o rebanho e que estava com o membro suspenso e com uma ferida próxima a região do fixador (Figura 2 A e B).

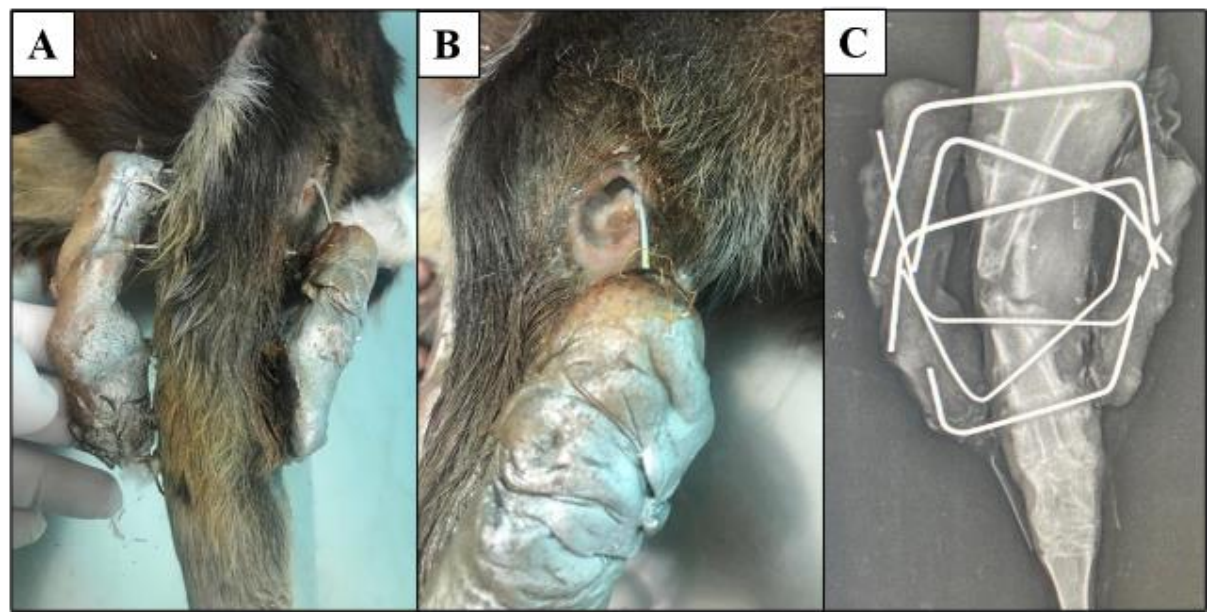

Figura 2. (A) Vista lateral de fixador esquelético externo em caprino. (B) Vista medial de fixador esquelético externo em caprino. Presença de ferida com secreção purulenta. (C) Imagem radiográfica na projeção craniocaudal, 68 dias após o procedimento cirúrgico, mostrando reabsorção óssea no foco da fratura e lise em torno dos pinos. 
O paciente então retornou ao HV-ASA e durante o exame físico, o animal apresentou os parâmetros vitais dentro da normalidade para a espécie, porém observou-se secreção purulenta drenando pelo trajeto dos pinos e por ferida penetrante na região lateral do membro pélvico (Figura 2 B), frouxidão dos pinos e dor à manipulação.

O animal foi medicado com tramadol $5 \%$ na dose de $2 \mathrm{mg} / \mathrm{kg}$ por via IM, e vinte minutos depois foi realizado o exame radiográfico da tíbia esquerda nas projeções CC e ML, que revelou não-união da fratura e reabsorção óssea no trajeto dos pinos (Figura 2C). Em seguida, o animal foi encaminhado para retirada do fixador esquelético externo.

Foi prescrito antibioticoterapia com Benzilpenicilina procaína, diidroestreptomicina e piroxicam (100 UI/mL) na dose $2.000 \mathrm{UI} / \mathrm{kg}$, uma vez ao dia durante cinco dias IM, dipirona $50 \%$ na dose de 25 $\mathrm{mg} / \mathrm{kg}$ a cada 12 horas durante cinco dias por via IM, e aplicação tópica de pomada cicatrizante, Ganadol ${ }^{\circledR}$ (penicilina $\mathrm{G}$ benzantina + penicilina G procaína + diidroestreptomicina + ureia) com açúcar nas feridas a cada 12 horas durante cinco dias depois de fazer a limpeza com solução fisiológica e clorexidine $2 \%$, até completa cicatrização.

Após vinte dias desse último atendimento, o animal retornou ao HV com as feridas cicatrizadas, sem dor à palpação e apoio intermitente do membro, podendo observar também um desvio no local da fratura devido à má união óssea.

\section{Discussão}

Apesar das fraturas ósseas serem afecções de menor incidência em pequenos ruminantes, elas são de extrema importância, pois trazem perdas econômicas para o rebanho. Borowsky et al. (2019) em seu estudo retrospectivo, no Hospital de Clínicas Veterinárias da Universidade Federal do Rio Grande do Sul em Porto Alegre, sobre afecções de ruminantes, de 2007 a 2018, observaram que dentre 341 ruminantes atendidos no Hospital Escola, apenas dois foram de caprinos com fraturas.

Em animais de produção, a alternativa mais frequente, principalmente em fraturas de ossos longos, é a eutanásia (Vechiato et al., 2009), pois geralmente há inviabilidade do tratamento pelo porte do animal, pelos cuidados necessários no pós-cirúrgico, além do fator financeiro. Porém, Câmara et al. (2014) afirmam que o tratamento conservativo com restrição de espaço do animal em baia, a confecção de imobilização externa e bandagens, pode mudar esse panorama, uma vez que apresenta baixo custo e os materiais são de fácil aquisição.

No presente relato optou-se inicialmente, pelo tratamento conservador, por ser um animal jovem e, portanto, a recuperação da fratura tende a ocorrer de maneira mais rápida e pelo interesse do proprietário em utilizar o animal na produção de leite.

A imobilização externa deve ser realizada de forma minuciosa por um profissional capacitado para sua realização adequada. Além disso, o animal deve ser sedado para promover o relaxamento do membro e assim facilitar o manuseio e tentativa de aproximação dos fragmentos ósseos (Câmara et al., 2014).

No presente relato, a primeira tentativa foi o tratamento com a imobilização externa de gesso sintético, a qual foi avaliada a eficácia por meio de radiografia após 15 dias. Observou-se que havia presença de reação periosteal na fatura, mas diante do desalinhamento e da não aposição dos fragmentos ósseos, a atividade biológica não estava no gap da fratura e o paciente ainda não estava apoiando o membro. Desta forma, e em decorrência do tempo de imobilização sem efeito, optou-se pela intervenção cirúrgica, a osteossíntese.

Aithal et al. (2010) afirmam em seu estudo que o tratamento conservativo com imobilização externa do membro de fraturas de tíbia não é eficaz, pois não estabilizam adequadamente a articulação fêmurotíbio-patelar, corroborando com relato em questão.

Neste animal foi utilizado FEE por ser mais versátil, de menor custo com relação aos outros implantes, invasão mínima da área traumatizada, facilidade de enxertia óssea e fácil de ser aplicado (Dória et al., 2010). O uso desse implante foi citado por vários autores como Zielinski et al. (2017), Vechiato et al. (2009) e Castelhano Júnior et al. (2019), dos quais relataram que os caprinos se adaptam 
bem a esse tipo de fixador, apoiando o membro no dia seguinte depois da cirurgia, corroborando com o presente relato.

No entanto, este tipo de osteossíntese não atinge estabilidade absoluta no foco de fratura quando comparado a outros métodos (Paretsis et al., 2016). O ideal para este tipo de fratura transversa seria um implante que oferecesse estabilidade absoluta como a placa de compressão dinâmica (Piermattei et al., 2009), porém, o seu custo-benefício inviabiliza a sua utilização para animais de produção.

Uma das particularidades que deve ser levada em consideração antes de uma intervenção ortopédica é o manejo pós-operatório (Zoppa et al., 2020), pois se não for bem executado, os riscos de complicações aumentam.

Além da técnica cirúrgica bem executada diante do tempo esperado para realização da intervenção cirúrgica, foi utilizado enxertia autóloga de medula óssea, que segundo Gomes et al. (2017) é uma das principais fontes de células-tronco mesenquimais que auxiliam na regeneração de tecidos, diferenciando de acordo com o local em que se encontram, e, no caso de ser aplicada na região óssea, essas células diferenciam-se em osteoblastos, reduzindo o tempo de cicatrização óssea.

Apesar de ser mais utilizada em pequenos animais, a aplicação de medula óssea também é encontrada em caprinos, no qual Sun et al. (2018) e Wang et al. (2018) utilizaram células da medula óssea para regeneração de cartilagem e obtiveram bons resultados.

Após o procedimento cirúrgico com aplicação da medula óssea, o caprino deste relato apresentou boa evolução do quadro clínico, percebendo melhora no apoio do membro ao caminhar com sustentação do peso, estando ativo, com apetite, sem sinal de dor e estabilidade da fratura percebido durante a limpeza do FEE e troca dos curativos. Vinte e cinco dias depois da cirurgia, o animal voltou a propriedade ainda com o FEE e foi solto com outros caprinos, não havendo a restrição ambiental e cuidados pós-operatórios recomendados, o que levou ao quadro de infecção e frouxidão do implante.

Após 68 dias do procedimento cirúrgico, na imagem radiográfica do membro, foi possível visualizar não-união do foco da fratura e áreas de lise óssea em volta dos pinos, devido a osteomielite.

Paretsis et al. (2016) em seu relato com uso de FEE tipo I em um caprino, observaram áreas de discreta lise óssea em torno dos pinos com 20 dias pós-cirúrgico, mas só retiraram os implantes com 45 dias, obtendo consolidação da fratura. Já Zielinski et al. (2017) observaram consolidação completa da fratura do caprino relatado após 60 dias de pós-operatório. Esses autores obtiveram sucesso que está relacionado ao acompanhamento pós-cirúrgico. Por outro lado, no estudo experimental com osteomielite em caprinos, de Tran et al. (2013), citaram que o reparo e a cura de fraturas podem ser complicadas pela presença de feridas abertas, lesões graves nos tecidos moles e contaminação ambiental, aumentando o potencial de infecção da ferida cirúrgica, osteomielite e retardo na união óssea.

Assim, é importante ressaltar que mesmo o animal passando por complicações pós-cirúrgicas, houve evolução do quadro clínico e no último retorno foi constatada a melhora do animal, pois houve união clínica da fratura e má união óssea, percebida através da formação de calo ósseo que foi sentida durante a palpação e apoio intermitente do membro, sugerindo que esta técnica seria uma boa alternativa em casos onde as imobilizações não sejam satisfatórias.

\section{Conclusão}

O presente relato conclui que apesar das complicações clínico-cirúrgicas, o animal se recuperou da fratura com o uso de fixador esquelético externo tipo II, pois mesmo não havendo a continuidade de manejo pós-cirúrgico adequado, houve união clínica da fratura.

\section{Referências bibliográficas}

Aithal, H. P., Kinjavdekar, P., Pawde, A. M., Singh, G. R., \& Setia, H. C. (2010). Management of Tibial Fractures Using a Circular External Fixator in Two Calves. Veterinary Surgery, 39(5), 621-626. https://doi.org/10.1111/j.1532-950X.2009.00643.X

Borowsky, A. M., Raimondo, R. F., Beck, C. A. C., Oberst, E. R., Rivero, B. R. C., Melo, L. C., Bueno, F. U., \& Loss, D. E. (2019). Estudo retrospectivo dos casos clínicos de ruminantes atendidos no 
Hospital de Clínicas Veterinárias da UFRGS. Acta Scientiae Veterinariae. Porto Alegre, RS. Vol. 47 (2019), Pub. 1625, 9 P.

Câmara, A. C. L., Calado, E. B., Paula, J. M. A., Antunes, C. M., Afonso, J. A. B., \& Azevêdo Costa, N. (2014). Tratamento conservativo e cirúrgico em 22 ruminantes com fraturas em membros 1. Pesquisa Veterinária Brasileira, 34(11), 1045-1050.

Castelhano Junior, A., Castelhano, C. A. F., Moreira, A. C. \& Yasuoka, M. M (2019). Utilização de fixador externo linear fixo para correção de fratura cominutiva em metacarpo em caprino: relato de caso. Revista saúde, v.13, n.2, ESP.

Conti, J. B., Schossler, J. E. W., Alievi, M. M., Bonfada, A. T., Novosad, D., Silva, D., \& Pachaly, J. R. (2007). Uso do fixador esquelético externo Tipo II para osteossíntese de tibiotarso em galinhas da raça Plymouth Rock Branca: modelo experimental para uso em aves selvagens. Pesquisa Veterinária Brasileira, 27(5), 199-204. https://doi.org/10.1590/S0100-736X2007000500003

Dória, R.G.S., Freitas, S.H., Mendonça, F.S., Pires, M.A.M., Santos, M.D. \& Camargo, L.M. (2010). Associação de aparelho em U a pinos transcorticais e gesso sintético na correção de fratura de segunda falange em equino adulto - Relato de Caso. Revista Brasileira de Medicina Veterinária, v.32, n.1, p.21-25

Gomes, I. S., Oliveira, V. C., Pinheiro, A. O., C.S.Roballo, K., Araujo, G. S. M., Veronezi, J. C., Martins, D. S., \& Ambrósio, C. E. (2017). Bone marrow stem cell applied in the canine veterinary clinics. Pesquisa Veterinária Brasileira, 37(10), 1139-1145. https://doi.org/10.1590/s0100-736x2017001000016

Paretsis, N. F., Andrade, F. S. R. M., Spagnolo, J. D., Ojeda, J. A. F., Nóbrega, F. S., Benesi, F. J., Corrêa, R. R., \& Zoppa, A. L. V. (2016). Utilização de fixador externo tipo I para correção de fratura de olécrano em caprino: Relato de caso. Pubvet, 10(12), 889-894. https://doi.org/10.22256/pubvet.v10n12.889894

Piermattei, B. D. L., Flo, G. L., \& Decamp, C. E. (2009). Ortopedia e tratamento das fraturas dos pequenos animais (3 ed.). Editora Manolo.

Sun, H., Huang, Y., Zhang, L., Li, B., \& Wang, X. (2018). Co-culture of bone marrow stromal cells and chondrocytes in vivo for the repair of the goat condylar cartilage defects. Experimental and Therapeutic Medicine. https://doi.org/10.3892/etm.2018.6551

Tran, N., Tran, P. A., Jarrell, J. D., Engiles, J. B., Thomas, N. P., Young, M. D., Hayda, R. A., \& Born, C. T. (2013). In Vivo Caprine Model for Osteomyelitis and Evaluation of Biofilm-Resistant Intramedullary Nails. BioMed Research International, 2013, 1-11. https://doi.org/10.1155/2013/674378

Vechiato, T. A. F., Siqueira, R. F., Coutinho, A., Marchioni, G. G., Kolber, M., Peixoto Júnior, K. C., Toffoli, P. Z., \& Zanco, N. A. (2009). Utilização de fixação externa em fratura de úmero em caprino. Arquivo Brasileiro de Medicina Veterinária e Zootecnia, 61(5), 1242-1245.

Wang, Z., Zhai, C., Fei, H., Hu, J., Cui, W., Wang, Z., Li, Z., \& Fan, W. (2018). Intraarticular injection autologous platelet-rich plasma and bone marrow concentrate in a goat osteoarthritis model. Journal of Orthopaedic Research ${ }^{\circledR}, 36(8), 2140-2146$. https://doi.org/10.1002/jor.23877

Zielinski, L., Becke, A. P. B. B., Barcellos, L. C., Silva, J. B. P., Sotelo, E. D. P., Filho, I. R. B., \& Dornbusch, P. T. (2017). Osteossíntese de fratura exposta em diáfise de rádio e ulna com fixador externo em um caprino - relato de caso. Revista Acadêmica: Ciência Animal, 15(Suppl 2), 109. https://doi.org/10.7213/academica.15.S02.2017.54

Zoppa, A. L. V., Silva, L. C. L. C., Corrêa, R. R., Spagnolo, J. D., Hagen, S. C. F., \& Souza, A. F. (2020). Fraturas em potros: Estudo retrospectivo de 31 casos (2008-2019)/Fracture in foals: retrospective study of 31 cases (2008-2019). Brazilian Journal of Animal and Environmental Research, 3(2), 358-371.

Recebido: 17 de junho, 2020 Aprovado: 20 de julho, 2020.

Disponível online: 23 de outubro, 2020.
Licenciamento: Este artigo é publicado na modalidade Acesso Aberto sob a licença Creative Commons Atribuição 4.0 (CC-BY 4.0), a qual permite uso irrestrito, distribuição, reprodução em qualquer meio, desde que o autor e a fonte sejam devidamente creditados. 